\title{
The Forth Industrial Revolution: New Paradigm of Society Development or Posthumanist Manifesto
}

\author{
Alla Kravchenko \\ Doctor of Philosophical Sciences, Professor, \\ Kyiv National University of Trade and Economics \\ (Kyiv, Ukraine) \\ E-mail: allusik_k@ukr.net \\ https://orcid.org/0000-0001-8429-2183 \\ Iryna Kyzymenko
}

Ph.D., Associated Professor, Kyiv National University of Trade and Economics

(Kyiv, Ukraine)

E-mail: irochka.irishka@gmail.com

https://orcid.org/0000-0002-2148-9488

The article proposes an analysis of socio-philosophical, philosophical, anthropological and ethical problems associated by the fourth industrial revolution. In the modern socio-humanitarian discourse (economy, management, sociology, etc.), a lot of knowledge was accumulated about the strategies for implementing this civilization jump, and the article is a response to the complex requirements for the synthesis of existing theories and the philosophical conceptualization of the challenges that the Fourth Industrial Revolution carries. The authors revealed the specificity of challenges (disembodiment, artificial intelligence, technological unemployment, etc.), which allows us to talk about the crisis of the anthropological project of the Modern era in the conditions of avalanche spread of technological innovations in the sphere of production, human everyday life and physicality. The possibilities of the theory of posthumanism for the analysis of the prospects of human development are demonstrated, as well as the potential of the ethical principle "responsible innovations" for the implementation of the principle of a new era in social practice.

Keywords: Fourth Industrial Revolution; future of humanity; evolution of society; posthumanism; cyber-physical systems; artificial intelligence; responsible innovations

Received: August 29, 2018; accepted: September 28, 2018

Philosophy and Cosmology, Volume 22, 2019: 120-128.

https://doi.org/10.29202/phil-cosm/22/10

(C) Kravchenko, Alla, 2019

(C) Kyzymenko, Iryna, 2019 


\section{Introduction}

For more than two years, the world intellectual community has been discussing the prospects for further development of mankind, using the metaphor of the fourth industrial revolution and the next era of Industry 4.0. This metaphor, conceptualized in Klaus Schwab's speech at the world economic forum in Davos (January 2016), outlines a new social ontology in which modern technology plays a crucial (if not key) role. It is no secret that the whole history of human civilization is directly related to the development of science and technology, at the same time, Forth Industrial Revolution carries a radically new formulation of the question of the relationship in the system of 'man-technology'. If the previous history of civilization implemented the principle of subordination of technology to man, their distinction in terms of physicality, the new era, which includes humanity, should be an era of partnership of advanced technology, artificial intelligence systems and man.

The philosophical level of problems associated with the establishment of a new social order, in its entirety is extremely difficult to outline. We will list only a part of them. One of the key principles that defined the ethics of any civilization was the idea of human finitude, the limit of human life. The rapid development of biomedical technologies makes these ethical canons if not shaken, then at least be rethought. Is a traditional anthropological and social project possible in the conditions of radical (possibly infinite) prolongation of human life? Jeff Noonan emphasizes that the immortality of artistic metaphor and science fiction has already passed into the status of a real scientific problem: "Today, the idea of immortality is no longer moderately a philosophical foil; it is a live and diversified scientific research program. The transition from idea to techno-scientific project makes the connection between immortality and human happiness less obvious than the first generation of critical theorists seemed to think... Underlie and direct the advances in molecular biology, genetics, artificial intelligence, robotics, and nanotechnology, which promise, according to their advocates, ultimate to overcome all internal biological causes of death" [Noonan, 2015: 39].

The fundamental components of the social architecture of the last centuries were economic laws. In the context of new roles assigned to robotics, production forces and industrial relations acquire new content, and the socio-humanitarian discourse includes the concepts of "technological unemployment", "cyber-physical systems", etc. The alienation of the third Millennium, the revision of the status of creativity in professional activities is only part of the problems associated with the delegation of traditional human functions to technology.

For modern philosophy, in the context of technological innovation, the vanguard leaves the problem embodiment, rather, (dis)embodiment: "Telepresence and virtual reality seem to revitalize the old Platonic and Cartesian dream of escaping the prison of the body" [De Mul, 2003: 257]. Technologies of telepresence and virtual reality, technological intervention in the body (artificial organs, etc.) give; on the one hand, more opportunities to actualize the potential of the individual and existential freedom, on the other hand, leave room for manipulative control "outside". For some philosophical concepts, not devoid of conspiracy orientation, the questions come to the fore, who is interested in the spread of technological innovations in the most important anthropological practices of man, is not the idea of obtaining absolute power over humanity? In the context of the new future human image, it is legitimate to raise the issue of civilizational perspectives when humanism gives way to posthumanism. 


\section{Industrial Revolution Concept in Contemporary Social Sciences}

The history of human development over the past three centuries demonstrates a series of intensive (revolutionary) changes in the industrial and, accordingly, social and economic spheres. Each of the industrial revolutions implemented an innovative approach that radically changed the traditional industrial approaches of its time, the way of life of the entire society and the individual.

The first industrial revolution marked the transition from manual labor to factory production, which was able to provide advances in mechanical engineering ( $18^{\text {th }}$ century). The driving force behind the second industrial revolution (the second half of the $19^{\text {th }}$ early $20^{\text {th }}$ century) was the invention of the conveyor, electrical, internal combustion engine, unification, automation, etc. The third industrial revolution (the end of the $20^{\text {th }}$ the beginning of the $21^{\text {st }}$ century) is an event that formalized the introduction of advanced information technologies in production, including in the field of energy (renewable energy, smart grid technology, hybrid engines, etc.). The fourth industrial revolution (since 2016) implements the trend of automation, robotics, artificial intelligence systems (Google, Siri, etc.), introduction of cyber-physical systems, etc. The logic of all four industrial revolutions, according to modern social philosophers, is a series of the following trends: Industry 1.0 Mechanization, Industry 2.0 — Automation, Industry 3.0 - Digitalization, Industry 4.0 Robotics [Posthuman world, 2018].

The chronology of industrial revolutions shows that the gaps between them are becoming smaller and smaller, which means that the world is becoming more dynamic. The logic of increasing consumption challenges the established social architecture every time, and the Fourth Industrial Revolution is no exception to this rule. In this regard, Keteryna Bondar also highlights the peculiarity of the fourth industrial revolution, when a new social reality offers a radical update of the traditional presented in the "man-machine": "The essence of every industrial revolution is to increase productivity. Three previous industrial revolutions were triggered by technical innovations... Now, though, we are in the middle of the fourth wave of the technological advances. The fourth industrial revolution is going to have more extensive impact triggered by Internet and allowing communication between humans and machines in Cyber-Physical Systems (CPS) through large networks. Industry 4.0 will make it possible to collect and analyze different data across machines, allowing faster, more efficient and more flexible processes to manufacture goods of higher quality at reduced cost" [Bondar, 2017].

We have demonstrated the chronology and briefly described the content of all four industrial revolutions. Further, in the article we specify the philosophical problems associated with the implementation of Industry 4.0 ideas in social practice. At the same time, challenges to the modern anthropological project occupy a special place among a wide range of philosophical problems. The range of alternative philosophical problems, for example, includes the prospects for the development of global science with associated problems of identity erosion, brain drain, digital inequality, etc. [Khrystenko, 2016; Savenkova \& Svyrydenko, 2018].

In addition, the number of problems includes a wide range of ethical problems associated with the transition to a new stage of socio-cultural development. The high status of science in social architecture logically leads to a high level of competition for leadership positions and, accordingly, material resources. This fact actualizes the issues of academic ethics, responsible innovation, plagiarism, etc. In this respect, we stand in solidarity with Denys Svyrydenko, who claims that "plagiarism is one of the powerful 'breaks' of modernization at the intellectual sphere" [Svyrydenko, 2016: 72]. 
We would also like to note that the rapid pace of transition of Industry 3.0 to Industry 4.0 is the result not only of objective transformative processes in science and society. Governments of economically developed countries and transnational corporations are implementing broad programs that create real socio-cultural preconditions for a civilizational leap. Yongxin Liao with a group of authors cites a non-exhaustive list of strategic programs that create the necessary climate for rapid transit here Industry 3.0 to Industry 4.0:

- Since 2011 the United States (US) government begin a series of national-level discussions, actions and recommendations, titled 'Advanced Manufacturing Partnership' (AMP), to ensure the US to be prepared to lead the next generation of manufacturing;

- In 2012, the German government passed the 'High-Tech Strategy 2020' action plan, which annually sets billions of euros aside for the development of cutting-edge technologies;

- The French government initiated a strategic review in 2013, named the 'La Nouvelle France Industrielle', in which 34 sector-based initiatives are defined as France's industrial policy priorities;

- In 2013, the United Kingdom (UK) government presented a long-term picture for its manufacturing sector until the year of 2050, called the 'Future of Manufacturing'. It aims to provide a refocused and rebalanced policy for supporting the growth and resistance of UK manufacturing over the coming decades;

- The European Commission lunched the new contractual Pubic Private Partnership (PPP) on 'factors of the Future (FoF)' in 2014. It is under the Horizon 2020 programme that plans to provide nearly 80 billion euros of available funding over 7 years (from 2014 to 2020);

- In 2014, the South Korea government announced the 'Innovation in Manufacturing 3.0' embodied that four propulsion strategies and assignments for a new leap of Korean manufacturing;

- The Chinese government issued the 'Made in China 2025' strategy alongside the' Internet Plus 'plan in 2015. It is the priorities of the ten fields in the manufacturing sector to accelerate the informatization and industrialisation in China;

- In 2015, the Japanese government adopted the 5th Science and Technology Basic Plan, where particular attentions have been paid to the manufacturing sector for realising its world-leading 'Super Smart Society';

- The Singapore government has committed \$19 billion to its RIE 2020 Plan (Research, Innovation and Enterprise) in 2016. Eight key industry vertical have been identified within the advanced manufacturing and engineering domain [Liao et al., 2017: 36093610].

\section{Klaus Schwab Theory of Forth Industrial Revolution: Key Issues for Humanity Development}

Before we make an explication of the key provisions of the theory of the fourth industrial revolution, outlined by Klaus Schwab, I would like to make a remark of a methodological nature. I would like to increase the validity of our further appeal to the methodology of posthumanism to the study, stressing that the very author of the concept of transition to the era called 'Industry 4.0', explains the challenges of anthropological character: "It is characterized by a fusion of technologies that is blurring the lines between the physical, digital, and biological spheres" [Shwab, 2016]. As we can see, the blurring of the boundaries 
between technology and man is the core idea in the concept of Industry 4.0, in turn, raising the relevant question of the revision of the modern anthropological project from the methodological standpoint of posthumanism.

In the proposed Klaus Schwab theory of the industrial revolution, it is assumed that the driving force of fundamental changes will be the following technologies: artificial intelligence, robotics, the Internet of Things, autonomous vehicles, 3-D printing, nanotechnology, biotechnology, materials science, energy storage, and quantum computing [Shwab, 2016]. As you can see, almost each of the proposed technologies can play a large (direct or indirect) role in changes in the anthropological practices of modern man or his physicality.

The fourth industrial revolution symbolizes the transition to an era in which the traditional Cartesian metaphor 'Cogito ergo sum' acquires a special status. Anthropological project of the Modern era was largely based on the understanding of man as a carrier of consciousness and it is the activity of human consciousness and allowed to give social relations certain stability. The era of Industry 4.0 is a space for the implementation of artificial intelligence technologies that are implemented in close connection with human intelligence (CyberPhysical Systems). On the one hand, we are talking about a fundamental revision of human anthropological practices, when most of the traditional human functions in production and everyday life are delegated to artificial intelligence systems, works, etc. On the other hand, in addition to anthropology, the social component is faced with challenges - many people will have to lose their jobs, conditions for social exclusion will be created (people of lowskilled professions will not be able to fit into the new demands of the labor market Industry 4.0). This was alarmed at the World Summit on Technological Unemployment (New York, September 29, 2015): “Accelerating technological employment will likely be one of the most challenging social issues in the 21 st Century. Never before in history are so many industries being simultaneously upended by new technologies. Though 'creative destruction', in which lost jobs are replaced with new ones will be a factor, our newest technologies have the clear potential to eliminate many more jobs than we create. With advanced technology at a geometric pace, robotics, artificial intelligence, 3D printing, and other innovations with enormous disruptive potential will soon hit the mainstream. Billions of people worldwide are currently employed in industries that will likely be affected - and billions of new entrants to the workforce will need jobs" [World Summit, 2015].

Outlining the fundamental provisions of the theory of Klaus Schwab, giving rise to talk about the fourth industrial revolution as a holistic complex phenomenon, it should also be emphasized that this theory is the object of criticism from different positions. As an example, one of the well-known researchers of the modernization processes of modern education, Michael A. Peters stresses the illegality of using the concept of "industry "for the current tectonic shift in the economy and production: "What characteristics the Fourth Industrial Revolution is the underlying digital logic that changes everything. While it is the means for massive automation and the decline of industrial jobs, it is itself not 'industrial'. This is what Schwab does not understand or theorise very well. An industrial technical system that had its beginnings in England and Scotland with the invention of a refined steam engine that could be applied to the textile industry has now been truly globalized, but it not just the extension of the scope and scale of industrialisation that has changed" [Peters, 2017: 3]. As part of our research, we distance ourselves from the complex theoretical and methodological development of the concept of the fourth industrial revolution, generally recognizing its heuristic for modern transformations. 


\section{Posthumanism Perspectives for Humanity at Industry 4.0 Epoch}

The answer to the question, what is a Man, tried to answer thinkers throughout the history of human civilization. As you know, the most large-scale this issue was investigated by representatives of the philosophical tradition of humanism, and the provisions of their theory did not lose their relevance until the second half of the $21^{\text {st }}$ century. Formation of postindustrial society and its derivatives (information society, knowledge society, smart society, etc.) gave reason to talk about the emerging and deepening crisis of the anthropological project of the Modern era. Stefan Herbrechter interestingly describes the nature of the anthropological turn in modern society, metaphorically speaking about the 'analog' era (humanist, literate, book or text-based), which is passing into the past, as well as the 'digital' (posthumanist, code, data or information-based) [Herbrechter, 2013: 4].

Homeostasis of technology and human physicality, virtual reality technology, achievements of cognitive Sciences, real practice of medical intervention in the human body with a change in the fundamental anthropological characteristics of man, such as gender, allow to manifest the need for revision of traditional (humanistic) presented in Man. In his fundamental work 'Posthumanism: a critical analysis', Stefan Herbrechter outlines the current challenges of the modern anthropological project as follows: "What is 'man'? This age-old question is everywhere today being asked again and with increased urgency, given the current technological developments leveling out our traditional humanist reflexes. What this development also shows, however, is that the current and intensified attack on the idea of a "human nature" is only the latest phase of a crisis which, in fact, has always existed at the center of the humanist idea of the human" [Herbrechter, 2013: 3].

In the sociohumanitarian discourse of recent decades, the revision of the anthropological project is carried out within the framework of two dominant and competing paradigms (posthumanism and transhumanism), offering scenarios for the development of mankind. Accordingly, each of them offers its own strategies for resolving the contradictions of scientific and technological progress, its own 'future human image', rationally assessing the possibilities and prospects of using the achievements of progress to change a person, extend his life expectancy, etc. For a correct understanding of the essence of posthumanistic theories, according to Jos de Mul, it should be borne in mind that the whole history of human development is associated with inventions that to varying degrees were a continuation, improvement of human physicality: "Human beings have always been cyborgs, that is, beings composed of both organic and technological components. Although technical and cultural artifacts such as knives, cars, books and computers are not part of the biological body, as soon as they become part of human life they also become part of the human body scheme and cognitive structure" [De Mul, 2003: 254].

A clear separation between the ideas of transhumanism and posthumanism is the subject of active discussion, which increasingly boils down to the understanding of transhumanism as one of the aims of posthumanism. The search for heuristic concepts for futurological research in the field of philosophical anthropology is carried out in the work of Francis Fukuyama 'Our posthuman future: Consequences of the biotechnology revolution' [Fukuyama, 2003]. However, as shown by a wide discussion on the pages of well-known scientific publications and this theory cannot claim to be complete.

Analyzing the difficulties in separating posthumanist and transhumanist concepts, Cary Wolfe emphasizes that some works assert the consistency of understanding of transhuman 
as a transition stage from man to posthuman [Wolfe, 2010: xiii]. Debate around the common and distinctive aspects of theories of posthumanism and transhumanism goes beyond the objectives of the article, so the text, in our opinion; correctly use the concept of posthumanism.

The above-mentioned work of Francis Fukuyama and most other well-known works offer a wide range of methodological guidelines and worldviews underlying them and determining the content of these theories. As an example, some posthumanist theories openly demonstrate a radical revision of the humanistic principle in favor of 'reasonable egoism' and narcissism with its craving for the infinite improvement of the human body, the triumph of the ideas of liberalism in the actual existence of the individual. Some theories are reduced to the study of the possibilities of posthumanism to implement in social practice the fundamental values of humanity (charity etc.), when technology advances allow us to change the lives of people with special abilities, to defeat the deadly disease, etc.

In which to our article, it was emphasized that the development of biomedical technologies and their introduction into medical practice is one of the important socio-cultural challenges of 'Industry 4.0'. Posthumanist discourse on the introduction of innovations in medical practice is broad: the challenges of eugenics are highlighted; the prospects of immortality and overpopulation of the planet; inequality in access to expensive technologies for different countries and social classes, etc. And if this discussion is futuristic character, at the policy level in the countries of the European Union is already talking about the aging of the European Nations as a challenge to the social order. The analysis conducted by Ulrike Bechtold and the team of researchers, demonstrates the unwillingness of the current social institutions act as a guarantor of sustainable development of society in terms of its continuous aging: "Policy discourse on the major challenges of demographic change in the coming years tends to focus on the future of ageing as a central problem, using phrases such as 'ageing Europe' and identifying problems such as a 'lack in care personnel' and 'difficulties in financing the baby boomers who start to retire"” [Bechtold et al., 2017: 162].

The modern civilization faces an important choice "to "bind" the civilization development by the anthropological project of the Modern era, or to legitimize one or several posthumanistic anthropological projects, introducing the achievements of modern science into everyday life and human embodiment. At the same time, the opacity of this choice lies in the fact that the global economy and transnational corporations will make this choice for all mankind, sacrificing the ethical principle of 'responsible innovations' in favor of the logic of consumption, leadership in world markets, etc. The logic of profit and expense does not allow for ethical verification of technological innovations, does not contain opportunities for futurological forecasts.

\section{Conclusions}

In the study, we were able to outline the problem field of challenges of the fourth industrial revolution anthropological project, established in the era of Modernity. It was possible to demonstrate the features of this civilizational leap, which is qualitatively different from the three previous revolutions, which changed the course of civilization. If the previous industrial revolution changed society is gradually taking over from human physical labor, then Industry 4.0 involves the rapid change in the practices of anthropological and social architecture: the innovations of the industrial revolution, suggesting robotization of production, the transfer of decision-making systems, artificial intelligence (cyber-physical systems), intervention into the human body and genetic code, etc. 
When we talk about the challenges of Industry 4.0 to human nature, we need to understand that technocratic ideology with its pathos of innovation is at the center of the ideological platform of this socio-cultural shift. In utopian posthumanist projects, we are talking about factories of new organs for people, and the concept of 'genetic engineering' is traditional for modern science. However, it is necessary to ask how possible 'engineering' in the field of human nature, because engineering is based on strict rationalism, belief in the power of technological progress, and considers efficiency and productivity as a criterion of its success? In the article, we have made an attempt to describe the possible challenges of the implementation of Industry 4.0 in social practice. We raised questions as far as possible from the point of view of modern philosophy, in particular the theory of posthumanism, the improvement of human nature.

The challenges of Industry 4.0 are in the focus of policy documents in the field of modern scientific research. In particular, the European science implemented in the framework of the strategy Horizon 2020, is preparing to move into a new phase, called Horizon Europe [Horizon Europe]. An integral part of the ethical platform of research projects in the near future, according to the documents of Horizon Europe, should be the principle of 'science with a mission'. Thus, science is relied upon to ensure the sustainable development of mankind, when any scientific innovation is commensurate with the potential threats from its implementation to humanity as a whole, when innovation serves the idea of sustainable development. It seems that the time has really come to consider the achievements of scientific and technological progress not only from the standpoint of productivity and utility, but also from the point of view of ensuring the ideology of responsible innovation. The focus on social significance, not just market value, should be an imperative for the direct implementation of Industry 4.0 ideology into social practice.

\section{[L] References}

Badmington, Neil, ed. Posthumanism. Macmillan International Higher Education, 2000. Baron, Naomi S. Shall We Talk? Conversing With Humans and Robots. The Information Society, Vol. 31, 2015: 257-264. http://dx.doi.org/10.1080/01972243.2015.1020211

Bechtold, Ulrike, Leo Capari, and Niklas Gudowsky. Futures of ageing and technology comparing different actors' prospective views. Journal of Responsible Innovation, Vol. 4, Issue 2, 2017: 157-176. http://dx.doi.org/10.1080/23299460.2017.1360721

Bicchi, Antonio and Guglielmo Tamburrini. Social Robotics and Societies of Robots. The Information Society: An International Journal, Vol. 31, Issue 3, 2015: 237-243. http:// dx.doi.org/10.1080/01972243.2015.1020196

Bondar, Kateryna. What is in reality Industry 4.0? 09.11.2017. http://innovacima.com/ en/2017/11/09/what-is-industry-4-0/

Bowman, Diana M., Hermann Garden, Clare Stroud, and David E. Winickoff. The neurotechnology and society interface: responsible innovation in an international context. Journal of Responsible Innovation, Vol. 5, Issue 1, 2018: 1-12. http://dx.doi. org/10.1080/23299460.2018.1433928

De Mul, Jos. Digitally Mediated (Dis)embodiment. Information, Communication \& Society, Vol. 6, Issue 2, 2003: 247-266, http://dx.doi.org/10.1080/1369118032000093914

Fukuyama, Francis. Our posthuman future: Consequences of the biotechnology revolution. Farrar, Straus and Giroux, 2003.

Herbrechter, Stefan. Posthumanism: A critical analysis. A\&C Black, 2013. 
Horizon Europe - the next research and innovation framework programme. 06.07.2018. https://ec.europa.eu/info/designing-next-research-and-innovation-frameworkprogramme/what-shapes-next-framework-programme_en

Khrystenko, Olga. Education of a Future Human is the Key to Solving the Global Problems Facing Humanity. Future Human Image, Vol. 3 (6), 2016: 46-52.

Liao, Yongxin, Fernando Deschamps, Eduardo De Freitas Rocha Loures, and Luiz Felipe Pierin Ramos. Past, present and future of Industry 4.0 - a systematic literature review and research agenda proposal, International Journal of Production Research, Vol. 55, Issue 12, 2017: 3609-3629. http://dx.doi.org/10.1080/00207543.2017.1308576

Noonan, Jeff. The Debate on Immortality: Posthumanist Science vs. Critical Philosophy. The European Legacy, Vol. 21, Issue 1, 2015: 38-51. http://dx.doi.org/10.1080/1084877 0.2015 .1092762

Peters, Michael A. Technological unemployment: Educating for the fourth industrial revolution. Educational Philosophy and Theory, 49:1, 2017: 1-6. http://dx.doi.org/10 .1080/00131857.2016.1177412

Posthuman world — the one of the future? 06.09.2018. https://medium.com/tech4planet/ posthuman-world-the-one-of-the-future-2515702fcc $8 \mathrm{~b}$

Savenkova, Liudmyla and Denys Svyrydenko. Academic Mobility and Academic Migration Issues: the Case of Ukrainian Higher Education. Interdisciplinary Studies of Complex Systems, No. 13, 2018: 57-65.

Schwab, Klaus. The Fourth Industrial Revolution: What it means and how to respond. World Economic Forum, 14.01.2016. https://www.weforum.org/agenda/2016/01/the-fourthindustrial-revolution-what-it-means-and-how-to-respond/

Svyrydenko, Denys. Plagiarism challenges at Ukrainian science and education. Studia Warmińskie, Vol. 53, 2016: 67-75.

Wolfe, Cary. What is Posthumanism? University of Minnesota Press, 2010.

World Summit on Technological Unemployment (New York), 29.09.2015. https://www.wtn. net/technological-unemployment-summit 